\title{
Medication Adherence in Rheumatoid Arthritis Patients: Older Is Wiser
}

\author{
Denise C. Park, $\mathrm{PhD},{ }^{\circ}$ Christopher Hertzog, $\mathrm{PhD},{ }^{+}$Howard Leventhal, $\mathrm{PhD},{ }^{\neq}$ \\ Roger W. Morrell, $\mathrm{PhD},{ }^{,}$Elaine Leventhal, $M D, P h D, "$ Daniel Birchmore, $M D$, , \\ Mike Martin, $\mathrm{Dr} \mathrm{Ph}^{,}$" and Joan Bennett, MPH
}

OBJECTIVES: To create a profile of individuals nonadherent to their medications in an age-stratified sample (ages 34-84) of community-dwelling rheumatoid arthritis patients. The relative contributions of age, cognitive function, disability, emotional state, lifestyle, and beliefs about illness to nonadherence were assessed.

DESIGN: A direct observation approach was used in conjunction with structural equation modeling. All participants were administered a preliminary assessment battery. Medications were then transferred to vials with microelectronic caps that recorded medication events for all medications for the next 4 weeks.

PARTICIPANTS AND SETTING: A volunteer sample of 121 community-dwelling rheumatoid arthritis (RA) patients were recruited from newspaper ads, posters, and via informal physician contact from private rheumatology practices in Atlanta and Athens, Georgia. Written verification of the RA diagnosis and a disease severity rating were obtained from personal physicians before patients were enrolled in the study. Patients were tested in a private physician's office, and their medication adherence was monitored electronically for a month in their every-day work and home settings.

MEASUREMENTS AND RESULTS: Structural equation modeling techniques were used to develop a model of adherence behavior. Cognitive and psychosocial measures were used to construct latent variables to predict adherence errors. The model of medication adherence explained $39 \%$ of the variance in adherence errors. The model demonstrated that older adults made the fewest adherence errors, and middleaged adults made the most. A busy lifestyle, age, and cogni-

This article was supported by Grant 3RO1-AG09868 awarded to Denise C. Park, Daniel Birchmore, and Christopher Hertzog from the National Institute on Aging. This paper was also supported by Grant AG11715 awarded to Denise C. Park as a research component of the Center for Applied Cognitive Research on Aging at the University of Michigan.

Address correspondence to Denise C. Park, PhD, Center for Applied Cognitive

Research on Aging, Institute for Social Resenrch, 426 Thompson St., The University of Michigan, Ann Arbor, MI 48106-1248.

From *The University of Michigan, Ann Arbor, Michigan; †The Georgia Institute of Technology, Atlanta, Georgia; †Rutgers University, New Brunswick, New Jersey; SThe University of Georgia, Athens, Georgia; IIUniversity of Medicine and Dentistry of New Jersey, Robert Wood Johnson Medical School, Newark, New Jersey; \#US Veterans Administration Hospital and Vanderbilt University, Nashville, Tennessee; and 9The University of Heidelberg, Germany. tive deficits predicted nonadherence, whereas coping with arthritis-related moods predicted adherence. Illness severity, medication load, and physical function did not predict adherence errors. Omission of medication accounted for nearly all errors.

CONCLUSION: Despite strong evidence for normal, agerelated cognitive decline in this sample, older adults had sufficient cognitive function to manage medications. A busy lifestyle and middle age were more determinant of who was at risk of nonadherence than beliefs about medication or illness. Thus, practicing physicians should not assume that older adults have insufficient cognitive resources to manage medications and that they will be the most likely to make adherence errors. Very busy middle-aged adults seem to be at the greatest risk of managing medications improperly. J Am Geriatr Soc 47:172-183, 1999.

Key words: aging; medication; memory; rheumatoid arthritis

A critical element in successful clinical treatment of a disorder is that patients take the medication that is prescribed for them. It is widely believed that nonadherence is a serious problem, with particularly high estimates of nonadherence for older adults ${ }^{1}$ and for individuals with chronic diseases such as rheumatoid arthritis (RA). ${ }^{2-4}$ Recent advances in microelectronic monitoring have provided good measurement of adherence behaviors. The Medication Event Monitoring System (MEMS) relies on microchip technology that provides detailed records about the frequency with which a medication bottle is opened, thus providing more accurate data than has been available in the past about medication-taking behaviors over long periods of time. The available data suggest that MEMS provides lower estimates of adherence behaviors than verbal reports or pill counts, in part because the timing of ingestion is measured precisely. ${ }^{5,6}$

Less clear from such data are the causes of nonadherence. Medication adherence is a complex behavior that is likely affected by patients' beliefs about their illness, the complexity of their medication regimen, their overall level of cognitive function, the severity of their illness, and even the nature of their illness. ${ }^{7-9}$ One might expect, for example, that a highly adherent individual would be a younger person, with a high level of cognitive ability, who was seriously ill, believed 
him/herself to be very ill, and had an illness that provided feedback about the condition, such as pain or rapid heart beat. In contrast, a less adherent individual might be an older adult who was unconcerned about the diagnosis of an illness, received little physical feedback regarding the disorder, as in the case of hypertension, and had limited cognitive resources for managing a complex medication regimen. Finally, the environment itself may contribute to nonadherence in that we often forget to perform important actions when we are very busy ${ }^{8}$; thus, individuals who have many demands on their time might also be at high risk of nonadherence.

The above analysis suggests that multiple variables contribute to medication nonadherence and that an understanding of its causes is likely to be incomplete if an exclusively medical, cognitive, or psychosocial approach is taken. Structural equation modeling permits one to evaluate the joint contributions of causative agents to a behavior. We used structural equation modeling in the present rescarch to assess the relative contributions of age, cognitive function, beliefs about illness, objective health status, life style, and affective state to medication adherence. Each of these domains (except busy lifestyle) has already been studied separately as a cause of nonadherence.

Leventhal and Cameron ${ }^{10}$ focus on beliefs and suggest that medication adherence is a self-regulatory process based on a patient's perceptions and beliefs about their illness. In support of this model, Taal et al. ${ }^{11}$ reported that beliefs about self-efficacy were related to good self-reports of adherence and coping with RA.

Park, ${ }^{12}$ on the other hand, has proposed a cognitive model and has suggested that age and declining cognitive ability are factors that may directly affect adherence or may underlie faulty representations that encourage nonadherence. There is little evidence in regard to this issue. Isaac, Tamblyn, and the McGill-Calgary Drug Research Team ${ }^{13}$ reported limited correlations between cognitive function and adherence in a sample of older subjects, but the sample consisted of only 20 adults, with a variety of disorders, and the observed relationships were weak. Conn et al. ${ }^{14}$ reported no difference in adherence in aged individuals with low and high MiniMental State Exam scores. ${ }^{15}$ Finally, others have taken a medical approach and have argued that medication load and illness severity are of primary importance in understanding who is nonadherent rather then focusing on belicfs or cognition. ${ }^{16-18}$

Unlike the earlier studies, the present investigation examined all of these causative factors together as potential determinants of the medication adherence of rheumatoid arthritis patients. We were particularly interested in the hypothesis that declining cognitive abilities that occur with age in normal, community-dwelling older adults may result in poor adherence to a medication regimen. For this reason, we selected an illness for which we expected adherence to be relatively good. Rheumatoid arthritis is a serious, debilitating autoimmune disorder that can be treated effectively with immunosuppressants, corticosteroids, and nonsteroidal antiinflammatory drugs. RA patients experience pain that can be managed with adherence to medications. They also often have a number of concomitant conditions and are typically on a high medication load. These considerations led us to believe that RA patients would be highly motivated to adhere to a medication regimen so that age-related cognitive decline would be likely to be a salient factor in any observed nonadherence.

\section{METHODS}

\section{Study Design}

We used a direct observation or survey approach to study adherence and the predictors of adherence. At the beginning of the study, a comprehensive assessment survey measured patients' cognitive function, self-reported health, affective state, beliefs about their arthritis and medications, functional capabilities, and pain. After this initial assessment, each one of the participants' medications was transferred to a separate medication vial outfitted with the MEMS technology. Patients used the MEMS vials for 4 weeks, and the date and time that each medication vial was opened was recorded via a microchip contained in the lid. When the patients returned at the end of 4 weeks, the information in the medication lids was downloaded into a computer file, providing a detailed record of medication-taking behavior for each medication.

\section{Sample}

Of the 122 community-dwelling individuals, aged 34 to 84 , diagnosed with RA and recruited to be in the study, a total of 121 (100 women and 21 men) participated in the study. Only one dropped out, because of transportation difficulties; all others completed the entire protocol. Participants were recruited from newspaper advertisements, posters placed in physicians' offices, and patient organizations. All potential participants provided a written diagnosis of RA from their personal physician before being admitted to the study. The participant's personal physician also provided a severity rating of the arthritis using the Arthritis Foundation ${ }^{19}$ rating scale from 1 (mild) to 5 (severe). Patients were taking a minimum of four prescribed medications, at least one of which was for RA and at least three of which had to be taken on a daily basis. The remaining medication could have been taken on an "as needed" basis. In addition, patients had a minimum eighth grade education, 20/30 corrected vision, and could also hear sufficiently well to converse normally on the phone with an interviewer during the initial screening interview. Patients had to be willing to come to an off-site testing station in a private physician's office in Atlanta or Athens, Georgia. Any individual who had been hospitalized in the past 6 months or who reported receiving assistance managing their medications was excluded. The Institutional Review Board at the University of Georgia approved this project, and written informed consent was obtained from the participants at the beginning of their first meeting with the experimenters. Individuals were paid $\$ 100$ for their participation. All payments to participants were completed after 2 weeks of the 4-weck participation.

The participants were well educated; $96 \%$ had completed high school, and $66 \%$ had completed some college. Participants were taking a mean of 4.18 prescription medications on a daily basis, and both physicians and patients rated their rheumatoid arthritis as "moderate" on a 5-point severity scale (means of 3.18 for patients and 3.20 for physicians), with no differences between patient and physician ratings. A mean of 25.9 symptoms and conditions was reported on the Medical History Checklist out of a possible total of 72 that could be reported on this assessment of all bodily systems. ${ }^{20}$ 
Table 1 summarizes basic participant characteristics across five age groups; there are no differences across these groups for symptoms, number of prescription medications, years since diagnosis, education, self-rated or physician-rated disease severity, and/or self-reported disability as measured by subscales from the Revised and Expanded Arthritis Impact Measure Scales Health Status Questionnaire (AIMS2). ${ }^{21}$ The six subscales of the AIMS2 that were assessed were mobility, walking and bending, hand and finger function, arm function, self-care tasks, and household tasks. Comparison of participants' mean levels of disability with the Meenan et al. ${ }^{21}$ standardization sample for the AIMS2 allowed us to evaluate the relative functioning of our sample compared with these normative data. Results from large-sample statistical tests for mean differences between these groups indicated that the present sample was significantly younger $(z=$ $3.32, P<.01)$, and more mobile $(z=3.14, P<.01)$ and better able to perform self-care and household tasks $(z=$ $2.63, P<.05, z=3.10, P<.05$, respectively) than the sample from the AIMS2. These data are presented in Table 2. Inasmuch as participants had to be sufficiently mobile to visit the field office for the assessment sessions, these differences were not surprising.

\section{Assessment Battery}

The instruments that patients completed are described below. All required multiple choice responses or Likert-scale checkoffs unless otherwise noted. The instruments were presented on computer screens, which participants completed by pressing designated buttons on a computer keyboard. This was less fatiguing for patients than writing and required less manual dexterity. As in our previous research, participants were enthusiastic about the computer, and even the oldest adapted easily. ${ }^{22}$ Screen displays were printed in large characters. All software was designed by a professional consulting agency to be suitable for use with older adults.

\section{Demographic Questionnaire}

A modified version of the OARS ${ }^{23}$ was used to obtain information on gender, age, education, profession, living arrangements, and income.
Table 2. Average Scores and Standard Deviations on AIMS2 Functioning and Pain Variables of Present Sample Compared with Meenan et al. (1992) Sample

\begin{tabular}{lrrrrr}
\hline \multicolumn{1}{c}{ Variable } & $\begin{array}{c}\text { Present } \\
\text { Sample } \\
(\mathrm{n}=120)\end{array}$ & \multicolumn{2}{c}{$\begin{array}{c}\text { Meenan } \\
\text { Sample } \\
(\mathrm{n}=299)\end{array}$} \\
\hline Age & 56.07 & $(12.74)^{*}$ & 60.70 & $(13.3)$ \\
Mobility & 1.11 & $(1.41)$ & 1.69 & $(2.28)$ \\
Walking and bending & 4.21 & $(2.46)$ & 4.58 & $(2.83)$ \\
Hand and finger function & 2.81 & $(2.28)$ & 3.16 & $(2.58)$ \\
Arm function & 1.85 & $(2.09)$ & 2.01 & $(2.26)$ \\
Self-care tasks & 0.36 & $(1.20)$ & 0.73 & $(1.53)$ \\
Household tasks & 1.06 & $(1.51)$ & 1.67 & $(2.43)$ \\
Pain & 4.99 & $(2.51)$ & 4.69 & $(2.52)$ \\
\hline
\end{tabular}

Norc: All AIMS2 items and scales were scored such that low scores indicate good health status whereas high scores indicate poor health status. Scale scores were calculated by summing the responses for all items in a particular scale. All scale scores were then standardized so that the best possible scale score was 0 and the worst possible score was 10.

* Standard Deviations are shown in parentheses.

\section{Health and Function}

Health Inventory. Participants were asked to check off items from a detailed list of past conditions and to present symptoms derived from the Medical Inventory Checklist. ${ }^{20} \mathrm{~A}$ total sum of items checked, as well as a weighted sum (with more serious symptoms and conditions given greater weight) was obtained.

Arthritis Pain, Stiffness, and Fatigue. An instrument modeled on the pain subscale of the AIMS2 ${ }^{21}$ provided an additional assessment of pain caused by arthritis and determined how much stiffness and fatigue the participants were experiencing. In this instrument, items from the AIMS2 pain subscale were expanded to include level of arthritis pain experienced in the morning, afternoon, and evening. Other items were added to assess how often arthritis pain interfered with activities, as well as questions about the duration of pain in the morning and the level of pain experienced after being physically active. Separate sections of this instrument in-

Table 1. Summary Statistics on Research Participants as a Function of Age

\begin{tabular}{|c|c|c|c|c|c|c|}
\hline \multirow[b]{2}{*}{ Variable } & \multicolumn{5}{|c|}{ Age Group } & \multirow[b]{2}{*}{$\mathrm{F}$} \\
\hline & $\begin{array}{c}34-44 \\
(n=27)\end{array}$ & $\begin{array}{c}45-54 \\
(n=33)\end{array}$ & $\begin{array}{c}55-64 \\
(n=25)\end{array}$ & $\begin{array}{c}65-74 \\
(n=25)\end{array}$ & $\begin{array}{c}75+ \\
(n=11)\end{array}$ & \\
\hline Gender & $\begin{array}{c}4 \text { Males } \\
23 \text { Females }\end{array}$ & $\begin{array}{c}3 \text { Males } \\
30 \text { Females }\end{array}$ & $\begin{array}{c}7 \text { Males } \\
18 \text { Females }\end{array}$ & $\begin{array}{l}4 \text { Males } \\
21 \text { Females }\end{array}$ & $\begin{array}{l}3 \text { Males } \\
8 \text { Females }\end{array}$ & \\
\hline Symptoms (number of health conditions) & $29.5(22.5)^{\star}$ & $26.4(15.5)$ & $28.9(15.8)$ & $19.3(13.2)$ & $23.7(11)$ & NSD \\
\hline Average number of medications & $4.4(1.5)$ & $4.3(1.2)$ & $4.5(1.3)$ & $4.0(1.0)$ & $3.7(0.6)$ & NSD \\
\hline Number of years since diagnosis ${ }^{\dagger}$ & $3.7(1.7)$ & $3.7(1.7)$ & $4.1(1.7)$ & $3.7(1.7)$ & $4.2(1.3)$ & NSD \\
\hline Disease severity rating by physician ${ }^{\ddagger}$ & $3.1(0.7)$ & $3.2(0.6)$ & $3.3(0.7)$ & $3.2(0.7)$ & $3.5(0.5)$ & NSD \\
\hline Disease severity rating by participant ${ }^{\ddagger}$ & $3.2(0.7)$ & $3.1(0.6)$ & $3.5(0.8)$ & $3.0(1.0)$ & $3.1(0.8)$ & NSD \\
\hline Years of education $\$$ & $3.3(1.1)$ & $3.2(1.1)$ & $2.9(1.1)$ & $2.8(0.9)$ & $2.6(1.1)$ & NSD \\
\hline
\end{tabular}

$t_{1}=$ less than one ycar; $2=1-5 ; 3=6-10 ; 4=11-15 ; 5=16-20 ; 6=$ over 20 .

$\$ 1=$ extremely mild; $2=$ mild; $3=$ moderate; $4=$ severc; $5=$ extremely severe.

$s_{1}=$ Grades 8-11; 2 = High School Degree; $3=$ Some College; $4=$ College Degree; $5=$ Post Graduate.

- Standard Deviations are shown in parentheses. 
cluded similar items to determine the amount of stiffness and fatigue participants experienced because of their arthritis. Items from The Multiple Affect Adjective Checklist-Revised (MAACL-R) were also administered to assess level of fatigue. $^{24}$

Functional Status. Mobility, walking, hand and finger function, arm function, and performance of self-care tasks, household tasks, and work were assessed by subscales of the AIMS2. ${ }^{21}$ A new summary scale was developed from the original AIMS2 items reflecting overall function. The pain and social support subscales from the original AIMS2 were also included.

Mental Health. Depression and well-being were assessed using the Center for Epidemiological Studies Depression Scale (CES-D). ${ }^{25,26}$ Items from the MAACL-R were also completed by participants to assess levels of depression and anxiety. ${ }^{24}$

\section{Illness and Medications Beliefs}

Arthritis Beliefs Questionnaire. A detailed series of questions regarding beliefs about rheumatoid arthritis was developed. This instrument was based on the Health Belief Questionnaire by Jette et $\mathrm{al}^{27}$; however, extensive changes to questions were made by the research team for use in this study. New items were added to assess knowledge about RA and its social and economic impact. Items were also revised to reflect the perceived severity of the participants' disease along the dimensions of time course and disease cues. Because Lorig and colleagues ${ }^{28,29}$ have shown self-efficacy to be important in adherence and treatment of arthritis, we elaborated on the self-efficacy construct by developing separatc subscales for different aspects of self-efficacy. These subscales addressed participants' perceptions of their ability to control (a) disease-related negative affect, (b) the activation and maintenance of disease and associated arthritis flares, in addition to Lorig's measures of (c) disease-related pain.

Medications Use and Beliefs Questionnaire. Participants answered general questions about how much help they reccived in taking medications and strategies they themselves developed for taking medications. Participants also completed questions about their beliefs about each of the medications they were taking: whether the medication helped them; whether they remembered to take it; and beliefs about side effects and whether it was an effective medication. These instruments were developed by the research team.

Additional questionnaires about medications and illness were completed for on opinions about taking medications, strategies for coping with arthritis, worry about illness, and amount of exercise.

\section{Contextual/Life Style Variables}

Participants completed two questionnaires in regard to this topic. One questionnaire was the "Busy Life Style Questionnaire." This questionnaire had two subscales: the first subscale consisted of nine questions that assessed how chaotic and unpredictable were participants daily lives (e.g., questions about how consistently bed times, meal times, and other activities were scheduled), and the second subscale was an 8-item "Busyness Scale" that assessed overall activity level (e.g., participants endorsed being so busy they couldn't remember to do everything they had to do). The second questionnaire had eight items, and it assessed participants' perceptions of social support across a number of domains (e.g., perceived reliability and assistance from friends or family members). This social support questionnaire was modeled after previous instruments developed by McFarlane et al. ${ }^{30}$ and Procidano and Heller. ${ }^{31}$

\section{Cognitive Assessment}

Participants completed a cognitive battery to assess multiple domains of cognitive function. ${ }^{32}$ Primary among these were measures of speed of information processing $g^{32,33}$ and on-line working memory capacity ${ }^{32,34}$ as there is substantial evidence for age-related declines of these functions. Additionally, Park ${ }^{12}$ has hypothesized that important cognitive components of medication adherence include (1) the ability to comprehend information present on labels, (2) reasoning and integrating medication instructions across prescriptions, and (3) long-term memory for the integrated regimen instructions, and, thus, these domains were assessed in the cognitive battery. Finally, a measure of vocabulary was used to characterize the general verbal ability of our sample. A summary of the specific tasks used appears below.

Speed of Processing. Two standard measures of perceptual speed were administered, a Letter Comparison task and a Pattern Comparison task. The Letter Comparison task, ${ }^{35}$ required participants to determine if two strings of letters were the same or different. Three sets of these comparisons were administered, each of which was comprised of either three, six, or nine letters. The dependent measure was the total number of correct decisions made in the three 30 -second periods. In the Pattern Comparison task, ${ }^{35}$ participants determined if geometric figures were the same or different, following the same format and timing as in the letter comparison task.

Working Memory. A Reading Span task and a Computation Span task were used to assess the on-line capacity of participants to simultaneously process and store information. The reading span task ${ }^{36}$ required participants to do three things. First, they were to read aloud a series of simple sentences that were presented on a computer screen one at a time. In addition to reading the sentence aloud, they were told to remember the last word in each sentence that they read. A third requirement was that they answer a simple question about each sentence. Thus subjects might read "The girl with the bat hit the ball." They would be expected to remember "ball" and answer a question like "With what?" At the end of a sentence series (which ranged from two sentences to seven sentences), subjects would be asked to recall the words they had been told to remember from the sentences. There were three trials in each series. The number of sentences a subject had to hold in memory was two in the first series and then increased one sentence each new series up to a total of seven sentences. The dependent measure was the number of trials in which the subject both recalled the words correctly and answered the questions correctly. The Computation Span task was identical to the reading span task except that the stimuli were equations (i.e., $2+4=$ ?). Participants solved the equations (tested in a 3 -item multiple-choice format) while holding the last digit in each equation in working memory.

Text Comprehension Measure. Two texts from a set of 25 structurally equivalent narrative texts specifically designed for use with older adults ${ }^{37}$ were administered as measures of text comprehension. The texts were presented individually on a computer screen and, after reading, participants 
were asked to recall five specific details about ideas presented in the text without the text present. The dependent measure was the total number of details correctly recalled from each of the texts.

Measure of Long-Term Memory. A free recall task was used as a measure of long-term memory. In this task, two lists of 25 different words each were presented to participants on a computer. ${ }^{32}$ Within each list of words were five categories of words and five exemplars presented for each category. The words were chosen from the Battig and Montague ${ }^{38}$ word norms. After the final screen from each list was presented, participants recalled as many items as they could in any order they chose. The main dependent variables were the number of words recalled and the number of categories accessed.

Reasoning Measure. The Letter Sets Test ${ }^{39}$ was used as a measure of reasoning. Each problem in this task had five sets of letters with four letters in each set. Four of the sets of letters were alike in some way (i.e., in alphabetical order). Participants were to find the rule that made the four sets alike and draw an X through the set of letters that were different. The participants had 7 minutes to complete 15 sets and the dependent measure was the number of sets completed correctly.

Vocabulary Measure. The Vocabulary section of the Shipley Institute of Living Scale ${ }^{40}$ is comprised of 40 multiple choice items of increasing difficulty. The participants were presented with a word and instructed to choose the one of the four available word choices with the same, or most nearly the same, meaning. The dependent measure was the total number of correct responses.

\section{Procedure}

On Day 1, the participants were given a brief overview of the study, and their vision was assessed via a Snellen Eye Chart. After this, they completed a series of cognitive tests. When the cognitive battery was completed, the experimenter reviewed in detail with the participants each medication that was being taken (name of medication, dosage, etc.). Participants were given empty medicine vials with plastic replacement caps and instructed to have their pharmacists transfer their medications into the new containers.

Participants returned for a second and final 2-hour session within a week of their initial visit. Upon return, the participants completed the psychosocial battery in a predetermined order. Participants were also provided diaries in which they were to note any problems with the MEMS system, changes in the medical regimen, or errors in using the MEMS system (opening the wrong medicine bottle). A fact sheet about the use of the MEMS caps and the diary was also reviewed with the participants. Participants were instructed to take their medications from the bottles that had been provided during the next 4 weeks, and whenever the MEMS cap was removed, the date and time the bottle was opened would be recorded. When the participants returned 4 weeks later, they turned in their medication bottles and completed a subset of the psychosocial battery to assess test-retest reliability of the instruments.

\section{Measurement of Nonadherence}

Nonadherence rates were calculated in a stringent manner designed to ensure that patients' behavior was not mistakenly tallied as nonadherence when, in fact, patients were following physician instructions. Any medications that were prescribed as PRN (take as needed) were not included in data analysis. Also, during the medication interview, participants sometimes indicated that they took the medication on a different schedule from that written on the prescription signature on the bottle, per their doctor's oral instructions. To resolve this disparity, the participant's personal physician was then contacted. If the physician verified the participant's report, the oral instructions were used as the basis for calculating adherence. Finally, diary notes were used to correct any apparent errors. For example, if a participant wrote that they took the medication out of the bottle and took it at a different time, the diary data was used to correct the data collected via the MEMS system. Diary notes were relatively rare and corrections were made less than $1 \%$ of the time $1.003 \%$ of data points changed because of participant errors, $.002 \%$ of data points changed because of changes in regimen by physician).

Weekly and biweekly adherence rates were calculated for each participant for each non-PRN, prescribed medication taken. The individual medication adherence rate was calculated separately for each medication by dividing the total number of medication errors in a weekly or biweekly period by the total number of medication events in that period. A medication error occurred if a participant either omitted a dose of medication or took an extra dose of medication. If a subject took an accurate number of doses on any given day, they were considered adherent. Thus, if a subject took two doses of medications at a closer interval than that recommended by the physician (e.g., every 8 hours), or at longer intervals, they would not be considered nonadherent. Nearly all of the errors made were omission errors. The rate for commission errors (taking an extra dose) was only $1.2 \%$. Preliminary analyses indicated it would most useful to calculate an aggregate measure of both types of errors (omission and commission) that were used for all analyses, as in Morrell et al. ${ }^{41}$ These preliminary analyses also showed no systematic differences in adherence rates across types of medication (i.e., arthritis, NSAIDs, antihypertension, thyroid, cardiovascular, gastrointestinal, antidepressant, folic acid, supplements, and other medications), and, therefore, proportions were averaged over all medications for each participant.

\section{RESULTS}

\section{Description of Nonadherence Behavior}

In the present study, a surprising $38 \%$ of the sample made no commission or omission errors in the month-long period of data collection. Perfect adherence was more common among older than among younger adults; i.e., $47 \%$ of the adults older than 55 years of age and $28 \%$ of adults aged 34 to 54 were perfectly adherent $\left(x^{2}=4.75, P<.03\right)$. Participants were taking an average of 4.18 prescribed medications daily, with a mean number of 1.35 doses per day per medication. This is a total of approximately 170 medications a month taken without a single error by more than one-third of the overall sample and nearly half of the older adults. The rates of adherence across weeks are shown in Table 3. An analysis of variance on the weekly data, with age as a between-groups factor and weeks as a repeated measure yielded only a significant main effect of Week $(F, 3,348=$ $4.26, P<.01$ ), with nonadherence increasing over weeks (overall means of $4.6 \%, 5.8 \%, 6.6 \%$, and $8.5 \%$ from Weeks 1 through 4, respectively). This increase in nonadherence 
Table 3. Average Proportion and Standard Deviation of Total Errors for Rheumatoid Sample by Weckly and Biweekly Periods

\begin{tabular}{ccccccc}
\hline & \multicolumn{5}{c}{ Monitoring Period } \\
\cline { 2 - 6 } Age Group & Week 1 & Week 2 & Week 3 & Week 4 & Biweek 1 & Biweek 2 \\
\hline $34-44(n=27)$ & $.06(.09)^{*}$ & $0.05(.08)$ & $.07(.10)$ & $.10(.14)$ & $.06(.08)$ & $.08(.11)$ \\
$45-54(n=33)$ & $.06(.11)$ & $.09(.14)$ & $.10(.15)$ & $.11(.15)$ & $.07(.11)$ & $.10(.14)$ \\
$55-64(n=25)$ & $.02(.06)$ & $.03(.06)$ & $.06(.12)$ & $.08(.20)$ & $.02(.05)$ & $.07(.16)$ \\
$65-74(n=25)$ & $.05(.11)$ & $.06(.17)$ & $.04(.14)$ & $.07(.17)$ & $.05(.14)$ & $.06(.16)$ \\
$75+(n=11)$ & $.03(.06)$ & $.07(.12)$ & $.03(.07)$ & $.04(.06)$ & $.05(.07)$ & $.03(.06)$ \\
\hline
\end{tabular}

* Standard Deviations are shown in parentheses.

across the monitoring period is consistent with previous research that has used electronic monitoring. Morrell and colleagues ${ }^{41}$ observed a statistically significant increase in the early phases of monitoring as did Park and colleagues. ${ }^{42}$

We were particularly interested in the relationship of age and cognitive function to medication adherence. Because of the low error rates in adherence, we considered the possibility that we had an elite sample of older adults with exceptional cognitive capabilities. Thus, it was important to characterize the participants with respect to cognitive function. Table 4 presents data for performance on the cognitive battery as a function of age, along with comparison data on the same measures collected from a community-dwelling, agestratified sample collected by Park et al. ${ }^{32}$ and recruited from

Table 4. Cognitive Function of Rheumatoid Sample witl Comparison Data on Nonarthritis Participants from Park et al. (1996)

\begin{tabular}{|c|c|c|c|c|c|c|}
\hline & \multicolumn{6}{|c|}{ Age Group } \\
\hline & \multicolumn{2}{|c|}{$30 \mathrm{~s}$} & \multicolumn{2}{|c|}{$40 \mathrm{~s}$} & \multicolumn{2}{|c|}{$50 \mathrm{~s}$} \\
\hline & $\begin{array}{l}\text { Arthritis } \\
(n=10)\end{array}$ & $\begin{array}{c}\text { Nonarthritis } \\
(\mathrm{n}=44)\end{array}$ & $\begin{array}{l}\text { Arthritis } \\
(n=38)\end{array}$ & $\begin{array}{l}\text { Nonarthritis } \\
(n=45)\end{array}$ & $\begin{array}{l}\text { Arthritis } \\
(n=25)\end{array}$ & $\begin{array}{l}\text { Nonarthritis } \\
(n=41)\end{array}$ \\
\hline \multicolumn{7}{|l|}{ Speed of processing } \\
\hline Pattern comparison* & $56.30(12.5)$ & $59.00(8.3)$ & $54.26(9.6)$ & $55.56(9.8)$ & $50.56(10.1)$ & $54.48(10.5)$ \\
\hline Letter comparison* & $40.30(7.7)$ & $41.59(8.1)$ & $38.87(6.4)$ & $36.98(7.6)$ & $34.28(7.3)$ & $35.46(7.7)$ \\
\hline \multicolumn{7}{|l|}{ Working memory } \\
\hline Computation $\operatorname{span}^{\dagger}$ & $8.40(2.3)$ & $9.14(3.3)$ & $7.37(3.6)$ & $7.57(2.7)$ & $7.40(3.1)$ & $7.05(3.0)$ \\
\hline Reading span ${ }^{\dagger}$ & $5.90(1.9)$ & $8.18^{\star}(2.7)$ & $6.11(2.3)$ & $7.59(3.0)$ & $5.68(2.2)$ & $6.95^{\star}(2.6)$ \\
\hline \multirow{5}{*}{$\begin{array}{l}\text { Episodic or long-term m } \\
\text { Free recall } \\
\text { World knowledge } \\
\text { Shipley vocabulary }\end{array}$} & & & & & & \\
\hline & $30.90(9.5)$ & $31.25(6.8)$ & $29.34(6.8)$ & $30.53(9.4)$ & $24.76(5.3)$ & $27.83(7.8)$ \\
\hline & $31.8 \quad(5.27)$ & $31.3 \quad(5.6)$ & $32.4 \quad(4.75)$ & $32.2(6.8)$ & $30.9 \quad(5.36)$ & $33.1 \quad(6.5)$ \\
\hline & \multicolumn{2}{|c|}{$60 \mathrm{~s}$} & \multicolumn{2}{|c|}{$70 \mathrm{~s}$} & \multicolumn{2}{|c|}{$80 \mathrm{~s}$} \\
\hline & $\begin{array}{l}\text { Arthritis } \\
(n=27)\end{array}$ & $\begin{array}{c}\text { Nonarthritis } \\
(\mathrm{n}=54)\end{array}$ & $\begin{array}{l}\text { Arthritis } \\
(n=17)\end{array}$ & $\begin{array}{c}\text { Nonarthritis } \\
(n=54)\end{array}$ & $\begin{array}{l}\text { Arthritis } \\
(n=4)\end{array}$ & $\begin{array}{c}\text { Nonarthritis } \\
(n=23)\end{array}$ \\
\hline \multicolumn{7}{|l|}{ Speed of processing } \\
\hline Pattern comparison* & $45.78(9.46)$ & $48.78 \quad(11.4)$ & $40.41(11.1)$ & $43.77 \quad(8.5)$ & $35.00(12.3)$ & $33.45(8.1)$ \\
\hline Letter comparison* & $32.59(7.9)$ & $32.30 \quad(5.8)$ & $31.82(8.7)$ & $30.59 \quad(4.9)$ & $24.00(4.8)$ & $23.30(5.4)$ \\
\hline \multicolumn{7}{|l|}{ Working memory } \\
\hline Computation span ${ }^{\dagger}$ & $4.96(3.08)$ & $7.24^{\star \star}(3.4)$ & $4.06(2.1)$ & $6.16^{\star \star}(2.5)$ & $3.50(1.7)$ & $4.36(3.0)$ \\
\hline Reading $\operatorname{span}^{\dagger}$ & $5.22(2.3)$ & $6.72^{*}(2.8)$ & $4.06(1.6)$ & $6.20^{\star \star}(2.5)$ & $3.00(0.8)$ & $4.61(2.0)$ \\
\hline \multicolumn{7}{|l|}{ Episodic or long-term memory } \\
\hline Free recall ${ }^{\ddagger}$ & $25.33(7.5)$ & $26.94 \quad(7.8)$ & $19.76(7.0)$ & $26.88^{* *}(8.2)$ & $14.75(7.3)$ & $18.26(6.7)$ \\
\hline \multicolumn{7}{|l|}{ World knowledge } \\
\hline Shipley vocabulary $\$$ & $30.7 \quad(7.02)$ & $34.5^{*} \quad(4.1)$ & $31.6 \quad(6.34)$ & $35.6^{* *} \quad(3.8)$ & $31.5(8.4)$ & $33.6 \quad(5.3)$ \\
\hline
\end{tabular}

"The dependent measure is the total number of correct decisions made in three 30-second periods.

tThe dependent measure is the number of trails in which both the processing and storage components are correctly completed.

FThe dependent measure is the total number of words recalled from two lists of 25 words.

The dependent measure is the total number of correct responses to 40 items.

Note. Small-sample statistical tests ( $t$ tests) for differences between average scores from participants in the present study and the Park et al. sample on the cognitive measures were performed within age group.

Statistical differences between the means: ${ }^{*} P<.05$; $* * P<.01$. 
the same demographic area (Atlanta and Athens, GA). These data indicate two things. First, the RA sample was characterized by significant age-related decline on basic processing abilities (speed, working memory, episodic memory, and reasoning), but no decline on the measure of world knowledge (Shipley vocabulary). ${ }^{40}$ One-way analyses of variance were conducted with age segmented by decades as the repeated measures variable. All $F$ values reported here had 4, $120 d f$ and significant values are .01 or greater. Both measures of speed yielded significant age differences: $F=7.14$ for Letter Comparison and $\mathrm{F}=8.52$ for Pattern Comparison, as did the two working memory measures $(F=6.008$ for Computation Span and 4.44 for Reading Span). There was also a significant age effect for Free Recall $(F=6.78)$. However, the $\mathrm{F}$ value for the Shipley Vocabulary was not significant $(\mathrm{F}(4,120)=.538, P>.78)$. This pattern of decrease in processing abilities but invariance in world knowledge as measured by Shipley Vocabulary is typical in the cognitive aging literature. ${ }^{41}$ Further evidence that the present sample was not elite in its cognitive abilities is that the level of cognitive function of the participants is roughly equivalent to or slightly lower than that of another age-stratified sample recruited from the same demographic area (Atlanta and Athens, GA). Small sample statistical tests ( $t$-tests) for differences between average scores from participants in the present study and the Park et al. sample on the cognitive measures were performed within age group. There were statistical differences between the means (.05 or greater) for Computation Span and Reading Span in the subjects who were 60 and 70 years old. In both cases, the subjects in the Park et al. sample evidenced performance superior to those in the present study, with the means shown in Table 4. The 70-year-old subjects in the Park et al. sample also performed significantly better than the subjects in the present study on Free Recall. Finally, the 60- and 70-year-old subjects in the Park et al. sample performed significantly better on the Shipley Vocabulary Test. These data clearly indicate that the high levels of adherence evidenced in the older adults in this study cannot be attributed to a particularly high level of cognitive functioning in the sample. Moreover, the excellent adherence combined with the clear age-related decline in cognitive processes suggests that normal age-related cognitive decline does not appear to be an important factor in understanding medication adherence in this sample of RA patients, despite many suggestions in the literature to the contrary.

\section{Structural Equation Model}

A structural equation model of adherence behavior was developed in order to assess the major hypotheses regarding the interrelationships among constructs and the relative contributions of age, cognitive ability, medical, psychosocial, and contextual variables to medication adherence. ${ }^{43}$ Structural equation modeling was used to understand the predictors of adherence rather than statistical techniques such as multiple regression and path analysis. Unlike regression, structural equation modeling permits the specification of both direct and indirect relationships among variables, providing more information about potential causal relationships than does regression analysis. Structural equation modeling differs from path analysis (which also permits specification of relationships) in that in structural models, latent variables or hypothetical constructs are measured by collecting multiple indicators of important constructs (e.g., a critical construct such as cognitive function or negative affect is measured by administering one or more tests or instruments that measure the same thing). Shared variance among these multiple measures forms the basis for the latent construct, providing increased power and reliability for explaining variance in the target behavior (in this case, medication adherence). We used LISREL-8, developed by Joreskog and Sorbom, ${ }^{44}$ a statistical package designed to develop structural equation models, for the modeling component of the analyses.

Despite the relatively low error rate, there was nevertheless sufficient variance in adherence to model it as a function of other predictor variables. Latent variables were constructed based on theoretical considerations as well as preliminary factor analysis of questionnaires and the examination of zero-order correlations among predictor variables. The outcome measure used in the structural equation model was nonadherence, with the data from Weeks 3 and 4 used as indicators of the behavior. The adherence measure was subjected to a logarithmic transformation to minimize the impact of a few extreme scores. Table 5 provides a correlation matrix of all of the indicators used in the model. A summary of the findings that guided the construction of the latent variable model is below.

\section{Medical Variables}

Preliminary analyses indicated that neither medical nor physical function variables were predictive of medication adherence. Both physician and patient self-rated measures of disease severity did not relate to adherence behaviors, nor did the number of medications patients were taking. Neither an unweighted or weighted version (with more serious symptoms receiving heavier weights) of the physical symptoms check-list health scale had predictive value. Similarly, no subscale measures of functional capabilities from the AIMS-2 predicted nonadherence. Self-reported measures of pain were also unrelated to adherence, nor did number of years since diagnosis relate to adherence. Thus, none of these variables are included in the final model.

\section{Cognitive Variables}

Based on preliminary analyses and theoretical considerations, measures of speed of processing, working memory function, episodic memory, and reasoning were included as indicators of a single latent construct of general cognition.

\section{ExternalAids}

We considered whether use of external aids correlated with adherence as such a relationship could mask the effects of decreased cognitive function. There were no age differences in the use of external aids (e.g., use of organizers, writing notes, or putting the medications in a prominent location), nor was there a relationship between the use of these strategies and medication adherence. To determine if individuals of low cognitive ability were more likely to use external strategies, we compared the lower third of the sample on cognitive ability with the rest of the sample, using $t$ tests on all of the external strategy variables. The only significant effect that emerged was that subjects with higher cognitive ability were more likely to write themselves notes as reminders $(t(119)=2.09, P=.04)$. Based on these comparisons, there was little evidence that low cognitive ability subjects were using more environmental supports for their adherence and compensating for their cognitive deficits. 
Table 5. Correlations Among Indicators in the Model

\begin{tabular}{|c|c|c|c|c|c|c|c|c|c|c|c|c|}
\hline & Age & $\begin{array}{l}\text { MAACL-R } \\
\text { Anxiety }\end{array}$ & $\begin{array}{l}\text { MAACL-R } \\
\text { Depression }\end{array}$ & $\begin{array}{l}\text { Letter } \\
\text { Sets }\end{array}$ & $\begin{array}{l}\text { Working } \\
\text { Memory }\end{array}$ & Speed & $\begin{array}{l}\text { Free } \\
\text { Recall }\end{array}$ & $\begin{array}{l}\text { Busy- } \\
\text { ness }\end{array}$ & $\begin{array}{l}\text { Mood } \\
\text { Control }\end{array}$ & $\begin{array}{l}\text { Self- } \\
\text { Efficacy }\end{array}$ & $\begin{array}{l}\text { General } \\
\text { Control }\end{array}$ & $\begin{array}{c}\text { Week } 3 \\
\text { Total } \\
\text { Errors }\end{array}$ \\
\hline $\begin{array}{l}\text { Negative affect } \\
\text { MAACL-R } \\
\text { Anxiety }\end{array}$ & -.03 & & & & & & & & & & & \\
\hline $\begin{array}{l}\text { Negative affect } \\
\text { MAACL-R } \\
\text { Depression }\end{array}$ & .04 & $.84^{\star \star}$ & & & & & & & & & & \\
\hline Letter sets & $-.45^{\star \star}$ & -.15 & $-.28^{\star \star}$ & & & & & & & & & \\
\hline Working memory & $-.40^{* *}$ & -.15 & $-.20^{*}$ & $.43^{\star \star}$ & & & & & & & & \\
\hline Speed & $-.51^{\star \star}$ & -.13 & $-.27^{\star *}$ & $.54^{\star \star}$ & $.42^{\star \star \star}$ & & & & & & & \\
\hline Free recall & $-.45^{n *}$ & $-.26^{* *}$ & $-.30^{\star \star}$ & $.51^{\star \star}$ & $.34^{\mathrm{k}}$ & $.58^{\star \star}$ & & & & & & \\
\hline Busyness & $-.28^{* *}$ & $.19^{\star}$ & .05 & $.27^{\star \star}$ & $.27^{\star \star}$ & $.40^{\star \star}$ & $.21^{*}$ & & & & & \\
\hline Mood control & .13 & $-.61^{\star \star}$ & $-.60^{\star \star}$ & .11 & .15 & .07 & .15 & -.11 & & & & \\
\hline Self-efficacy & $-.21^{*}$ & $-.29^{\star *}$ & $-.29^{* *}$ & $.22^{*}$ & $.22^{*}$ & .17 & $.23^{*}$ & -.13 & .10 & & & \\
\hline Pain control & -.15 & $-.23^{*}$ & $-.19^{\star}$ & .17 & .16 & $.28^{\star \star}$ & $.26^{*}$ & .00 & $.29^{\star \star}$ & .02 & & \\
\hline $\begin{array}{l}\text { Week } 3 \text { Total } \\
\text { errors }\end{array}$ & $-.27^{\star \star}$ & $.28^{* *}$ & .17 & .02 & .01 & .07 & -.03 & $.32^{n \star}$ & $-.34^{* *}$ & $-.20^{*}$ & -.16 & \\
\hline $\begin{array}{l}\text { Week } 4 \text { Total } \\
\text { errors }\end{array}$ & -.15 & $-.19^{*}$ & .10 & -.12 & -.13 & -.02 & -.00 & $.33^{\star *}$ & $-.29^{* *}$ & -.13 & $-.18^{\star}$ & $.62^{* *}$ \\
\hline
\end{tabular}

$* P<.05 ; * * P<.001$.

We did observe, however, a weak but significant relationship between using the specific strategy of taking medications out of bottles and putting them into something else (e.g., an organizer), and medication adherence did occur ( $r=$ $.18, P<.04)$. We also found that people who reported being busy were somewhat more likely to report writing notes to remind them to take medications $(r=.19, P=.03)$. Finally, complexity of medication regimen correlated with the propensity to take the medications out of bottles $(r=.18, P<$ .04). None of these relationships was sufficiently strong to include in the model.

\section{Context/Life Style Variables}

The Busyness Scale was used as a measure of environmental demands and busy life style. Measures of social support did not correlate with adherence.

\section{Beliefs About Illness Control}

Because of the importance of beliefs about controllability of various aspects of disease in our theorizing and that of others, ${ }^{7,10,28,29}$, three separate controllability constructs were developed, each based on a subscale of three or more questions. The constructs were beliefs about ability to control pain (e.g., "I know I can manage arthritis pain so I can do the things I enjoy doing."), beliefs about ability to control disease activity (e.g., "I think that there are lots of things I can do to prevent my arthritis from getting worse."), and beliefs about ability to control negative moods relating to arthritis (e.g., "I know there are things I can do to help me feel better when my arthritis makes me feel blue."). Preliminary analyses suggested that these are independent constructs so they were represented in the model separately. We also examined whether individuals who had been diagnosed with arthritis longer had more knowledge about the disease. This correlation was not significant, nor was knowledge of disease related to adherence.

\section{Negative Affect}

Because beliefs about control could be related to overall levels of negative affect, a general construct called "negative affect" was included in the model, measured by the MAACL-R scales of Anxiety and Depression. We examined the measures of coping in some detail, as we had extensive measures of coping behavior, but we could not find any systematic relationships between styles of coping and adherence, nor did we see systematic relationships between coping styles and control.

\section{AModel of Adherence Behavior}

A structural equation model was estimated using Joreskog's ${ }^{43}$ procedures. In constructing the model, we conceptualized age and negative affect as variables that were conceptually more removed from the target behavior of medication adherence and likely to have both direct and indirect effects on the target behavior of medication adherence (e.g., negative affect might directly impact on medication nonadherence as well as indirectly affect other behaviors that relate to nonadherence). Cognitive function and contextual busyness were hypothesized to have direct effects on adherence, as were the various measures of disease self-efficacy. The model we developed is displayed in Figure 1 and, largely, confirmed these hypothesized relationships. The model explained $39 \%$ of the variance in nonadherence and had an excellent fit $\left(\chi^{2}\right.$ $(56)=70.34, P=.09$, nonnormed fit index $=.96$, comparative fit index $=.97$, root-mean-square residual $=.650$, and standardized root-mean-square residual $=.065$ ). There is no single criterion, nor are there reference tables to assess goodness of fit of structural equation models. Rather, multiple indicators of fit are considered jointly in assessing overall fit. Generally, a model that has excellent fit would have the following characteristics: (1) the chi-square index of fit is nonsignificant, indicating that the observed and estimated 


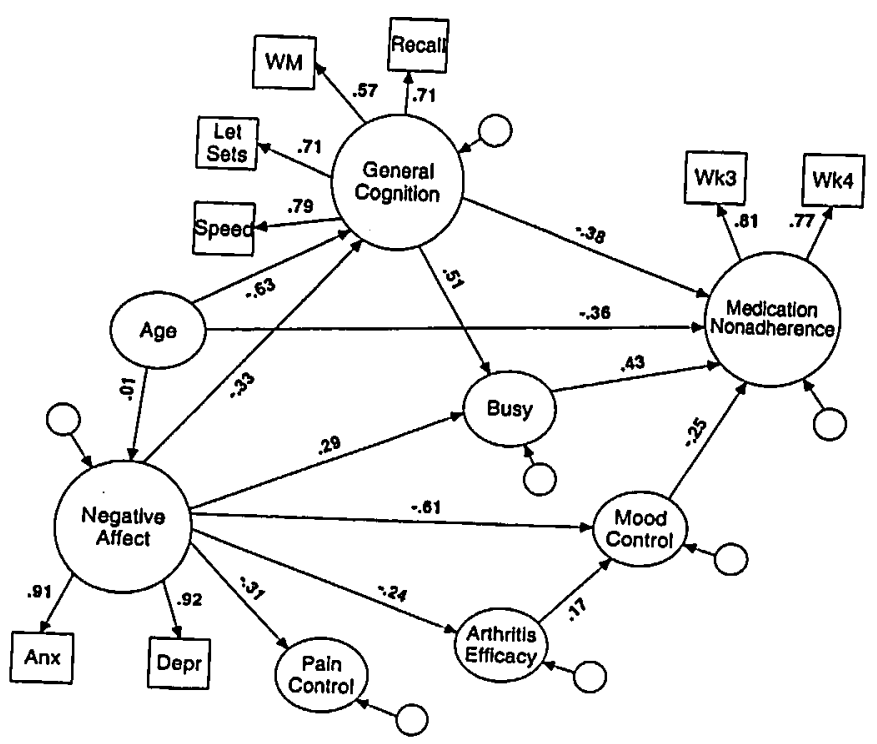

Figure 1. A model of adherence behavior.

models are not different; (2) the nonnormed fit index and comparative fit index are greater than .90 as a value of 1.0 indicates perfect fit; (3) the standardized root-mean-square residual is about .05 as this is the estimate of error. The present model meets these criteria, particularly the goodness of fit criterion, with only a slightly increased error estimate (.065) from the desired level of .05 . Table 6 presents unstandardized regression equations and standard errors for the model.

The standardized coefficients are included in Figure 1. The model demonstrates that age, cognitive function, and ability to control illness-related negative moods all have direct paths to medication adherence. Of particular interest is that age has a negative relationship to nonadherence, that is, with increasing age, adults evidence more rather than less adherence. The context in which adherence occurs appears to be important as well, inasmuch as individuals who report themselves as having a very busy life have higher nonadherence rates. Although preliminary zero-order correlations indicated that cognitive function did not have a direct relationship to nonadherence, it appears that age acted as a suppressor for the general relationship of cognitive function to adherence. Thus, once the direct negative relationship of age to cognitive function is controlled, individuals with low cognitive function do show poorer adherence. With respect to efficacy and control, only the self-reported ability to control negative affect associated with disease, but not control of pain or general disease activity, had a direct relationship to adherence. We did try a general model where overall arthritis self-efficacy (with each type of efficacy as an indicator) mediated the relationship, but the fit of this model was poor. General negative affect (as measured by anxiety and depression) mediated variance in both mood and arthritis efficacy as well as in self-reports of busyness and general cognitive function. The relationships were such that high negative affect is related to poorer cognitive function, decreased feelings of efficacy, and higher reports of contextual engagement. Finally, some age-related variance in nonadherence is unexplained by any variables in the model because age exerts a direct effect on nonadherence in addition to the strong age path operating through cognition.

Overall, this model demonstrates powerful relationships of cognitive, contextual, and affective variables to medication nonadherence. We were unable to establish any relationships involving traditional medical variables - such as symptomatology, number of medications, or disease severity - to medication nonadherence. The model suggests that the profile of a nonadherent individual with rheumatoid arthritis would most likely be a middle-aged adult of lower cognitive ability who reports being very busy or contextually engaged, has some anxiety/depression, and believes they have little ability to control negative affect associated with disease symptomatology.

\section{DISCUSSION}

The present findings make a number of important points that have largely been unrecognized in understanding patient adherence to a medical regimen. First, age is indeed a risk factor for nonadherence, but it is younger rather than older adults who are more at risk for making medication errors. Despite the suggestion that older people have a high nonadherence rate because of cognitive dysfunction, our data indicate clearly that maintaining a medication regimen does not impose a cognitive load that is so high that older adults have insufficient cognitive function to adhere accurately. The data show that older adults evidenced significant cognitive decline relative to younger adults but still had sufficient cognitive resources to take medication with an extraordinary degree of accuracy. This finding is largely in agreement with that reported by Park and colleagues ${ }^{42}$ and Morrell and col-

Table 6. Unstandardized Maximum Likelihood Estimates for the Structural Model

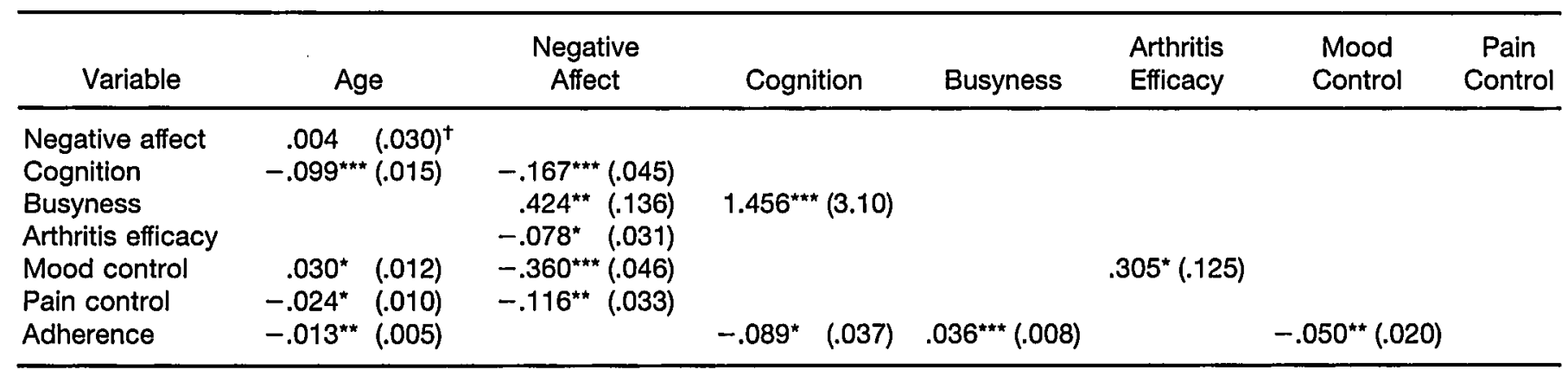

Note: $* P<.05 ; * * P<.01 ; * * P<.001$.

†'tandard Errors shown in parentheses. 
leagues $^{41}$ as both studies report very high adherence for adults ages 60 to 75 .

The high adherence rates in the older RA patients is likely due to vigilance about their health because RA is a serious illness with many symptoms that can interfere with daily function. Leventhal et al. ${ }^{45}$ noted more vigilance in monitoring health and seeking health care in older compared with younger adults. This vigilance may prevent them from getting into risky situations that requirc complex care and medical interventions if they are left untreated. ${ }^{46}$ We have noted in working with older patients, particularly those with a serious illness such as RA, that the patients frequently structure their daily activities around their medication schedules rather than the reverse. These experienced, older users of medication are in contrast to younger adults, who tend to fit medication events into their daily schedules. The finding that individuals who report being very busy were the most nonadherent supports such an interpretation. It would appear that very busy people are essentially operating under high memory load conditions with many tasks and situations simultaneously competing to capture their attention. Remembering to take medication for these individuals becomes problematic, not because they have insufficient cognitive function to perform the task, but because little of their cognitive resource is being devoted to the task of remembering to take medications. The busyness finding does not allow us to make inferences about what type of memory is most affected by being busy. Busy individuals may not take the time to understand or learn their drug regimen, which would point to problems in comprehension or long-term memory. Or busy people may both understand and remember what it is they are to do but have trouble with the prospective component, that is, remembering to take the drug at the time they are supposed to take it. Thus, more work is required to understand what the cognitive underpinnings of this effect are. Another explanation for the relationship of being busy to poor adherence is that busy people have little time to muse or think about their illness and do not have a representation of their illness that leads to a motivation to take the medication. However, the memory explanation seems more likely because we did not find evidence that busy people have different belief structures regarding their illness. In sum, the data suggest that being a very busy person mitigates against accurate use of medication because of an overly full life that leaves little time to attend to health concerns. In contrast, being old does not put one at risk of nonadherence, in part because older people may be less busy in their daily lives and have more time to devote to health concerns.

Another important finding from the present study is the overall high rate of medication adherence observed in the cntire sample. Participants were much more accurate in their use of medications than has been suggested in the RA literature, where less accurate means of monitoring have been used. Thirty-eight percent of patients made no mistakes at all in their complex regimens throughout a 1-month period of observation!

It is, therefore, relevant to emphasize that the present sample of RA patients was somewhat positively selected with respect to functional limitations imposed by RA (e.g., restricted mobility) and with respect to exclusion criteria (selfvs other-administered medications) that would limit representation of individuals with the most severe impairments. Clearly this aspect of the study would also tend to exclude extremely ill, frail, homebound older patients who might be at greatest risk for nonadherence. Thus, our generalizations regarding a lack of effect of age-related cognitive decline are limited to what is termed normal or primary aging and would not necessarily characterize cognition-related adherence deficits in RA patients with co-occurring dementia or other major pathologies that would limit ability to care for oneself.

There are other aspects of the study that may have acted to enhance adherence rates relative to other studies. This study assessed volunteer patients who were aware that their behavior was being observed, which may have enhanced adherence. Moreover, RA is a serious illness, which provides frequent feedback, in the form of pain and decreased mobility, for which medication is needed. This no doubt serves to enhance medication adherence for RA relative to other diseases. Morrell et al. ${ }^{41}$ observed higher rates of adherence crrors in hypertension patients who receive no physical feedback about their condition. Additionally, the decision to screen carefully and exclude PRN medications, as well as to resolve differences between physicians' verbal instructions and instructions on the prescription signature, may have resulted in a lower estimate of errors than has been reported by others. Finally, it is important to note that we studied experienced medication users, who were in treatment for their disorder. Higher rates of nonadherence may be found in inception samples if they are followed from initial diagnosis. Such samples are more likely to include a subset of patients who receive diagnosis of a disorder such as RA but do not take prescribed medication and seek no further treatment.

It is interesting that constructs such as perceptions of illness, self-efficacy beliefs, and other psychosocial variables that others have hypothesized to be important in understanding adherence ${ }^{10,28,29}$ appear not to have played a strong role in the RA patients' adherence. It may be the case that the importance of these variables depends on the kind of disease process that is under treatment. The impact of the relationship of these variables, although not important in the present study and sample, might be significant in samples with very high rates of nonadherence or for disorders that are silent, such as hypertension, or for diseases where the perceived and actual consequences of nonadherence are less compelling (i.c., osteoarthritis). ${ }^{47}$ In these cases, one might expect beliefs and emotional status to be more important.

Although the data make a strong case that older adults are at low risk for taking medications incorrectly, the cognitive model of medication adherence is not invalidated by the present data. There was a significant path from general cognitive function to nonadherence once the variance in cognitive function caused by age was removed, as shown in the model displayed in Figure 1. This finding suggests that individuals of low cognitive status relative to others their own age will have more problems taking medication accurately. In other words, a younger adult of low ability, or an older adult who has low ability relative to others their own age, will be at some risk of nonadherence. This is an important finding because it indicates that laboratory measures of cognitive function, when considered in context as is the case with the present modeling techniques, can explain variance in important every day behaviors. This finding also points to problems with comprehension and long-term memory rather than prospective memory (remembering when to take a medication) as the basis for the nonadherence in low-ability adults. The items used to form the cognitive variable are associated with 
comprehension and long-term memory, but not prospective memory, suggesting that additional time spent making sure low ability individuals comprehend their drug regimen would be worthwhile.

It is important to consider the clinical implications of the present findings. These data suggest that an individual who was highly adherent would most likely be old (contrary to popular memory stereotypes of older people), less busy, have high positive affect, and would believe that he/she could control any depression and anxiety associated with the disease. The clinical profile of a nonadherent individual would be a very busy, somewhat unhappy, young or middle-aged adult of low cognitive ability. An effective intervention for nonadherence for such an at-risk individual could take multiple forms. First, a physician could prescribe simpler drug regimens whenever there was a choice for an at-risk individual and ask staff to spend more time educating the patient about his/her condition, when he/she was to take the medications, and determine that the patient comprehended what to do. Second, for a complex regimen, it would be worthwhile to consider providing a medication organizer, but care needs to be taken to see that the patient knows how to load it correctly. Park and colleagues ${ }^{48}$ reported that arthritis patients made errors in loading organizers; but if it is loaded correctly, Park et al. ${ }^{42}$ found that organizers improved medication adherence in older adults. Finally, it might be worthwhile to consider using an external reminding device, such as a beeping wristwatch, to remind the patient to take their medications, an intervention that Park, Shifren and colleagues found to be effective with hypertensive patients. ${ }^{49}$

In closing, this pattern of findings makes a strong case for considering that the context in which illness occurs, as well as the nature of the illness itself, is important in understanding adherence behaviors. Individuals with a less painful disease, one in which clinical symptoms are less well controlled by medications, might well present a different profile. Nevertheless, our data indicate clearly that nondemented older adults appear to have all of the features necessary to be adherent. Although we found strong evidence for normative age-related decline in cognitive function, the baseline level of cognitive ability was still easily sufficient to adhere to a complex regimen.

\section{ACKNOWLEDGMENTS}

The authors are grateful to Denise L. Taylor-Moon for assistance in manuscript preparation.

\section{REFERENCES}

1. Botelho RJ, Dudrak R. Home assessment of adherence to long-term medication in the clderly. J Fam Pract 1992;35:61-65.

2. Beck NC, Parker JC, Frank RG et al. Patients with rheumatoid arthritis at high risk for noncompliance with salicylate treatment regimens. J Rheumatol 1988;15:1081-1084.

3. Belcon $\mathrm{MC}$, Haynes RB, Tugwell P. A critical review of compliance studies in rheumatoid arthritis. Arthritis Rheum 1984;27:1227-1233.

4. Blechman W. Managing the older arthritic: Can the family help? Geriatrics 1984;39:131-132.

5. Matsuyama JR, Mason BJ, Jue SG. Pharmacists' interventions using an electronic inedication-cvent monitoring device's adherence data versus pill counts. Ann Pharmacother 1993;27:851-855.

6. Mason BJ, Matsuyama JR, Jue SG. Assessment of sulfonylurea adherence and metabolic control, Diabetes Educ 1995;21:52-57.

7. Park DC. Self-regulation and control of rheumatic disorders. In: Maes S, Leventhal $\mathrm{H}$, Johnston M, eds. International Handbook of Health Psychology. New York: Wiley, pp 189-218.

8. Park DC, Kidder DP. Prospective memory and medicntion adherence. In:
Brandimonte M, Einstein GO, McDaniel MA, eds. Prospective Memory Theory and Applications. Hillsdale, NJ: Lawrence Erlbaum, 1996, pp 369-390.

9. Park DC, Mayhorn CB. Remembering to take medications: The importance of nonmemory variables. In: Herrmann DM, Hohnsonm M, McEnvoy C, Hertzog C, eds, Research on Practical Aspects of Memory, vol 2. Hillsdale, NJ: Lawrence Erlbaum, 1996, pp 95-110.

10. Leventhal $H$, Cameron L. Behavioral theories and the problem of compliance. Paticnt Educ Counsel 1987;10:117-138.

11. Taal E, Rasker JJ, Seydel ER, Wiegman O. Health status, adherence with health recommendations, self-efficacy and social support in patients with rheumatoid arthritis. Patient Educ. Counsel 1993;20:63-76.

12. Park DC. Applied cognitive aging research. In: Craik FIM, Salthouse TA, eds. The Handbook of Aging and Cognition. Hillsdale, NJ: Lawrence Erlbaum, 1992, pp 449-493.

13. Isaac LM, Tamblyn TM, and The McGill-Calgary Drug Research Team. Compliance and cognitive function: $A$ methodological approach to measuring unintentional errors in medication compliance in the elderly. Gcrontologist 1993;33:772-781.

14. Conn VS, Taylor SG, Miller R. Cognitive impairment and medication adherence. J Gerontol Nurs 1994;20:41-47.

15. Folstein MF, Folstein SE, McHugh PR. Mini-Mental State: A practical method for grading the cognitive states of patients for clinicians. J Psychiatr Res 1975;12:189-198.

16. Bergman U, Wiholm B. Patient medication on admission to medical clinic. Eur J Clin Pharmacol 1981:20:85.

17. Law R, Chalmers C. Medicines and elderly people: A general practice survey. BMJ 1976;1:565-568.

18. Shimp LA, Ascione FJ. Causes of medication misuse and error. Generations 1988;12:17-21.

19. Arthritis Foundation. Primer on the Rheumatic Discases. Atlanta, GA: Author, 1988.

20. American Rheumatism Association. Medical History Checklist. Atlanta, GA: American Rheumatism Association, 1987.

21. Meenan RF, Mason JH, Anderson JJ et al. AIMS2. Arthritis Rheum 1992; $35: 1-10$.

22. Echt KV, Morrell RW, Park DC. The effects of age and training formats on basic computer skill acquisition in older adults. Educ Gerontol, 1998;24:324.

23. Duke University Center for the Study of Aging and Human Development. OARS Multidimensional Functional Assessment Questionnaire Durham, NC: Author, 1975.

24. Lubin B, Zuckerman M, Hanson PG, Armstrong T. Reliability and validity of the Multiple Affect Adjective checklist - Revised. J Psychopathol Behav Assess 1986;8:103-117.

25. Hertzog C, Van Alstine J, Usala et al. Measurement properties of the Center for Epidemiological Studies Depression scales in older populations. J Consult Clin Psychol 1990;2:64-72.

26. Radloff LS. The Ces-D scalc: A self-report depression scale for research in general populations. Appl Psychol Meas 1977;1:385-401.

27. Jette $A M$, Cummings KM, Brock BM et al. The structure and reliability of health belief indices. Health Serv Res $1981 ; 16: 81-98$.

28. Lorig KR, Chastain RL, Ung $E$ et al. Development and evaluation of a scalc to measure perceived self-efficacy in people with arthritis. Arthritis Rheum 1989;32:37-44.

29. Lorig KR, Cox T, Cucbas $Y$ et al. Converging and diverging beliefs about arthritis: Caucasian patients, Spanish speaking patients, and physicians. J Rheumatol 1984;11:76-79.

30. McFarlane AH, Neale KA, Norman GR et al. Methodological issues in developing a scalc to measure social support. Schizophr Bull 1981;7:90-100.

31. Procidano ME, Heller K. Mcasures of perceived social support from friends and family: Three validation studies. Am J Community Psychol 1983;11:124.

32. Park DC, Snith AD, Lautenschlager $G$ et al. Mediators of long-term memory performance across the life span. Psychol Aging 1996;11:621-637.

33. Salthouse TA. The processing-speed theory of adult age differences in cognition. P'sychol Rev 1996;103:403-428.

34. Stine EL, Wingfield A. Process and strategy in memory for speech among younger and older adults. Psychol Aging 1987;2:272-279.

35. Salthouse TA, Babcock RL. Decomposing adult age differences in working memory. Dev Psychol 1991;27:763-776.

36. Salthouse TA, Babcock RL. Computation and Listening Span. Atlanta, GA: Georgia Institute of Technology, 1990.

37. Dixon R, Hultsch D, Hertzog C. A Manual of 25 Three-Tiered Structurally Equivalent Texts for Use in Aging Research. Technical Report, No. 2, Collaborative Group on Cognitive Aging, 1989.

38. Battig WF, Montague WE. Category norms for verbal items in 56 categories: A replication and extension of the Connecticut category norms. J Exp Psy- 
chol Monogr 1969;80:1-46.

39. Ekstrom RB, French JW, Harman HH, Dermen D. Kit of Factor-Referenced Cognitive Tests. Princeton, NJ: Educational Testing Service 1976.

40. Shipley WC. Shipley Institute of Living Scalc. Los Angeles: Western Psychological Services, 1986.

41. Morrell RW, Park DC, Kidder DP, Martin M. Adherence to antilypertensive medications across the life span. Gerontologist 37: 609-617.

42. Park DC, Morrell RW, Frieske D, Kincaid D. Medication adherence behaviors in older adults: Effects of external cognitive supports. Psychol Aging 1992;7:252-256.

43. Joreskog KG. Testing structural equation models. In: Bollen KA, Long JS, eds. Testing Structural Equation Models. Newbury Park, CA: Sage, 1993.

44. Joreskog KG, Sorbom D. Lisrel8 User's Reference Guide. Chicago: Scientific Software International, 1993.

45. Leventhal EA, Leventhal $H$, Schacfer P, Easterling D. Conservation of en- ergy, uncertainty reduction and swift utilization of medical care among the clderly. J Gerontol 1993;48:78-86.

46. Leventhal EA, Crouch M. Are there differences in perceptions of illness across the lifespan? In: Petrie KJ, Wcinman JA, eds. Perceptions of Health and Illness: Current Research and Applications. Amsterdam: Harwood Academic Publishers, 1997, pp 77-102.

47. Meyer D, Leventhal H, Gutmann M. Common-sense models of illness: The example of hypertension. Health Psychol 1985;4:115-135.

48. Park DC, Morrell RW, Frieske D ct al. Cognitive factors and the use of overthe-counter medication organizers by arthritis patients. Hum Factors 1991; 33:57-67.

49. Park DC, Shifren K, Morrell RW, Watkins K. The use of cognitive interventions to improve medication adherence in African-Americans with hypertension. Paper presented at the Gerontological Socicty of America, November 1997, Philadelphia, PA. 